\title{
Utilizing Electroplex Emission to Achieve External Quantum Efficiency up to $18.1 \%$ in Nondoped Blue OLED
}

\author{
Xuejun Zhan, ${ }^{1}$ Zhongbin Wu, ${ }^{2}$ Yanbin Gong, ${ }^{1}$ Jin Tu, ${ }^{1}$ Yujun Xie, ${ }^{3}$ Qian Peng, ${ }^{4}$ Dongge Ma, ${ }^{5}$ \\ Qianqian $\mathrm{Li}^{1}{ }^{1}$ and Zhen $\mathrm{Li}{ }^{10}{ }^{1,3}$ \\ ${ }^{1}$ Department of Chemistry, Sauvage Center for Molecular Sciences, Wuhan University, Wuhan 430072, China \\ ${ }^{2}$ Changchun Institute of Applied Chemistry, The Chinese Academy of Sciences, Changchun 130022, China \\ ${ }^{3}$ Institute of Molecular Aggregation Science, Tianjin University, Tianjin 300072, China \\ ${ }^{4}$ Institute of Chemistry, The Chinese Academy of Sciences, Beijing 100190, China \\ ${ }^{5}$ State Key Laboratory of Luminescent Materials and Devices, South China University of Technology, Guangzhou 510640, China
}

Correspondence should be addressed to Dongge Ma; msdgma@scut.edu.cn and Zhen Li; lizhen@whu.edu.cn

Received 17 August 2019; Accepted 19 December 2019; Published 27 February 2020

Copyright (C) 2020 Xuejun Zhan et al. Exclusive Licensee Science and Technology Review Publishing House. Distributed under a Creative Commons Attribution License (CC BY 4.0).

\begin{abstract}
For the first time, electroplex emission is utilized to enhance the performance of nondoped blue organic light-emitting diodes (OLEDs). By decorating the twisted blue-emitting platform and adjusting the electronic structure, three molecules of $3 \mathrm{Cz}-\mathrm{Ph}-$ $\mathrm{CN}, 3 \mathrm{Cz}-\mathrm{mPh}-\mathrm{CN}$, and $3 \mathrm{Ph}-\mathrm{Cz}-\mathrm{CN}$ with a donor-acceptor structure are synthesized and investigated. When external voltage is applied, electroplex emission, which contributes to the emission performance of OLED, can be realized at the interface between the emitting layer and the electron-transporting layer. Accordingly, high external quantum efficiency of $18.1 \%$ can be achieved, while the emission wavelength of the device can be controlled in the blue region. Our results provide the possibility to enhance the performance of OLED through electroplex emission, in addition to the generally investigated thermally activated delayed fluorescence (TADF). Excitedly, when $3 \mathrm{Ph}-\mathrm{Cz}-\mathrm{CN}$ is used as host material in orange-emitting phosphorous OLEDs (PO-01 as the dopant), unprecedented high external quantum efficiency of $27.4 \%$ can also be achieved.
\end{abstract}

\section{Introduction}

Since its discovery in the last century, thanks to unremitting efforts of scientists, organic electroluminescence has witnessed great progress [1-7]. Up to date, organic lightemitting diodes (OLEDs) could even be partially commercialized in full-color flat panel displays and solid-state lighting sources. However, to make full use of the formed excitons and reduce losing energy, it is still essential to seek excellent materials for OLEDs with enhanced light-emitting performances [8-10]. For typical nondoped fluorescent OLEDs, only the singlet $\left(\mathrm{S}_{1}\right)$ excitons corresponding to about $25 \%$ of the total electrogenerated excitons could be used [11, 12]. The resultant low external quantum efficiency inspired the utilization of phosphorous OLEDs, which employ transition metal (such as Os, Pt, and Ir) complexes as the emitter [13]. While heavy-atom-induced spin-orbit coupling could make it possible for effectively harvesting triplet excitons (75\% of the total electrogenerated excitons) [14], accompa- nied with higher external quantum efficiencies, the notorious stability problem and difficulty to tune the phosphorous emission of phosphorous OLEDs (PhOLEDs) bothered their wide applications. Besides triplet-triplet annihilation (TTA) $[15,16]$, pioneered by Uoyama et al., thermally activated delayed fluorescence- (TADF-) based OLEDs have been proposed to harvest both singlet and triplet excitons [17]. The theoretical possibility to fully (100\%) make use of the electron-generated excitons was intriguing, and lots of high efficiencies have been reported. However, TADF materials with blue emission were still scarce. The red-shifted emission and stability of the TADF-based OLEDs still need to be further improved though several encouraging examples have been reported [18-20]. Alternatively, other approaches which could efficiently make use of the excitons formed inside the OLED devices still needed to be explored.

Considering the above molecular designs carefully, all the attempts are utilizing the intramolecular excitons. Actually, taking TADF as an example, the excited states with essential 

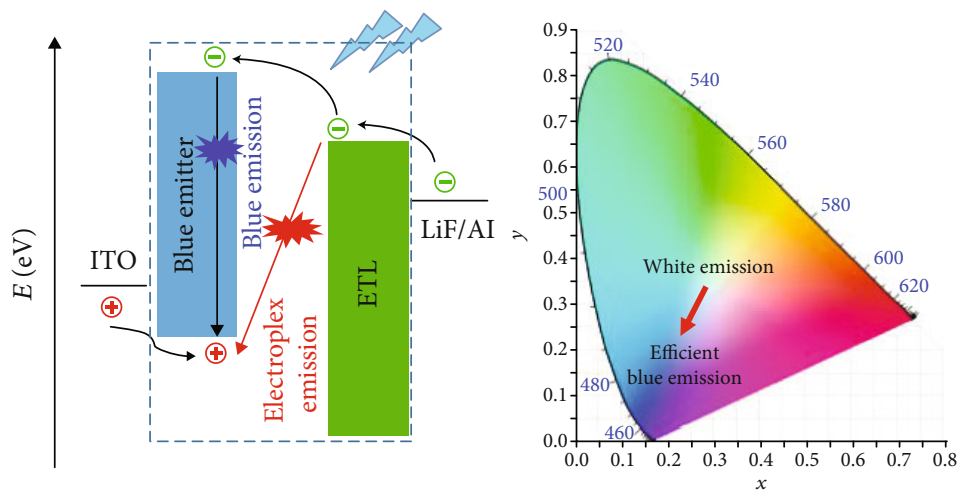

Scheme 1: Schematic description of the route to utilize exciplex/electroplex emission in blue OLED.

small $\Delta E_{\mathrm{ST}}$ can also be achieved by exciplex excitons, which can be generated by two oppositely charged molecules with weak Coulomb interactions [21]. Early in 1999, reported by Shirota et al., electron-transporting material of $5,5^{\prime}$-bis(dimesitylboryl)-2,2'-bithiophene (BMB-2T) was found to form an exciplex with the hole-transporting material of TPD at the interface [22]. After that, the EL efficiency and stability of bilayer-type exciplex OLED could be improved stepwise [23-25], indicating that it was possible to utilize intermolecularly formed excitons for the enhancement of the OLED performance. Actually, electroplex [26], similar to exciplex, was also a transient donor-acceptor complex between the excited state of the donor and the ground state of the acceptor. But different from exciplex, the newly formed peaks in EL spectra caused by the electroplex emission could not be observed in the PL spectra of the blend films of donor and acceptor molecules. Generally, the newly formed redshifted broad bands were employed to realize white emission $[27,28]$, and there were no efforts of using electroplex or exciplex to enhance the device performance while controlling the red-shifted bands. In recent years, our group has focused on the research of blue OLEDs with the emphasis on the design of blue and deep-blue AIEgens (Chart S1) [29-31]; accordingly, we wondered that if we choose a deep-blue emitter with the properly controllable red-shifted bands, the overall blue emission OLED with high performance should be possible by utilizing the formation of electroplex or exciplex (Scheme 1).

Twisted architecture has been proved to be effective for the realization of deep-blue emission [31]; thus, the easily modified 2,4,6-tribromobenzonitrile unit was chosen as the construction core. Carbazole, a good hole-transporting moiety which is easy to generate electroplex/exciplex [27], was employed to be the periphery substitution. To subtly adjust the distribution of electrons, here, three carbazole-based luminogens of $3 \mathrm{Cz}-\mathrm{Ph}-\mathrm{CN}, 3 \mathrm{Cz}-\mathrm{mPh}-\mathrm{CN}$, and $3 \mathrm{Ph}-\mathrm{Cz}-\mathrm{CN}$ were synthesized with different linkage models. Excitedly, electroplex could be formed at the interface between the emitting layer (EML) and the electron-transporting layer (ETL), when $3 \mathrm{Ph}-\mathrm{Cz}-\mathrm{CN}$ was used as EML in nondoped OLEDs. As expected, the high external quantum efficiency of $18.1 \%$ could be achieved, while the emission wavelength of the device could be controlled in the blue region. To the best of our knowledge, this is the first time that electroplex has been successfully utilized to enhance the performance of nondoped blue OLEDs. Furthermore, by utilizing 3Ph$\mathrm{Cz}-\mathrm{CN}$ as host material in orange-emitting PhOLEDs (PO-01 as the dopant), unprecedented high external quantum efficiency of $27.4 \%$ could be realized. Herein, we would like to present the synthesis and thermal, photophysical, electrochemical, and electroluminescent properties in detail.

\section{Results}

2.1. Synthesis and Characterization. Through cyanation and the followed Suzuki coupling reactions, all the cyanocontaining luminogens (Figure 1) were easily synthesized and purified by column chromatography with fine to good yields (Scheme S1). Compared to $3 \mathrm{Cz}-\mathrm{Ph}-\mathrm{CN}$, due to the larger intramolecular twisting degree [29], 3Cz-mPh-CN and $3 \mathrm{Ph}-\mathrm{Cz}-\mathrm{CN}$ exhibited better solubility. Their chemical structures were definitely characterized by ${ }^{1} \mathrm{H}$ and ${ }^{13} \mathrm{C}$ NMR, mass spectrometry, and elemental analysis. Thermal properties of the new luminogens were investigated by thermogravimetric analysis (TGA) and differential scanning calorimetry (DSC) measurements (Figure S1). As expected, owing to the good thermal stability of carbazole units, all the carbazole-containing luminogens were thermally stable with high $T_{\mathrm{d}}$ (corresponding to $5 \%$ weight loss) values surpassing $500^{\circ} \mathrm{C}$. Generally, because of the more rigid conformations, compounds with para-linkage mode show better thermal stability than those with meta-linkage way [29]. Thus, among them, $3 \mathrm{Cz}-\mathrm{Ph}-\mathrm{CN}$ exhibited excellent thermal stability with the $T_{\mathrm{d}}$ value of $550^{\circ} \mathrm{C}$, much higher than that of $3 \mathrm{Cz}-\mathrm{mPh}-\mathrm{CN}\left(504^{\circ} \mathrm{C}\right)$ with the meta-linkage mode. The glass transition temperatures $\left(T_{\mathrm{g}}\right)$ for $3 \mathrm{Cz}-\mathrm{Ph}$ $\mathrm{CN}, 3 \mathrm{Cz}-\mathrm{mPh}-\mathrm{CN}$, and $3 \mathrm{Ph}-\mathrm{Cz}-\mathrm{CN}$ were 165,121 , and $141^{\circ} \mathrm{C}$, respectively. These high $T_{\mathrm{g}}$ values could guarantee proper operating stability of the fabricated OLED devices [8].

2.2. Optical Properties. Absorption spectra of the carbazolebased luminogens in dilute THF solutions showed two bands located at 290 and $340 \mathrm{~nm}$ (Figure 2(a)), which could be ascribed to the carbazole-centered $n-\pi^{*}$ transition and intramolecular charge transfer (ICT) transition, respectively. In $\mathrm{UV}$-vis spectra, $3 \mathrm{Cz}-\mathrm{Ph}-\mathrm{CN}$ showed red-shifted absorption 

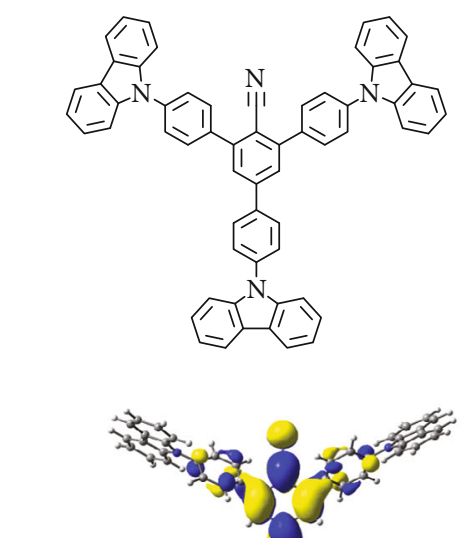

LUMO

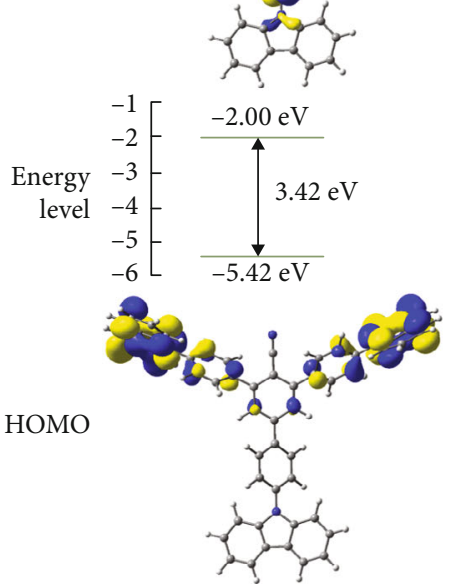

(a)
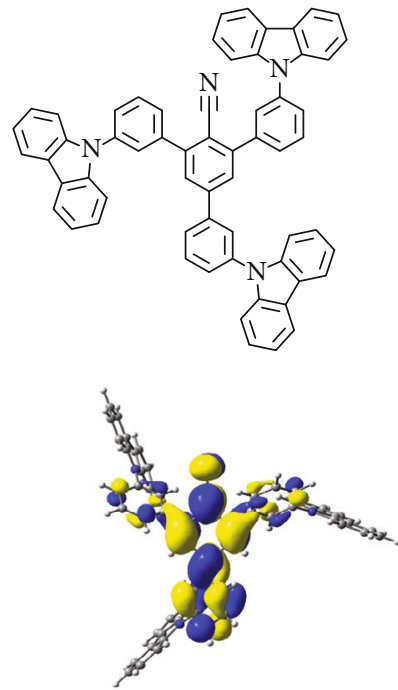

$-1.99 \mathrm{eV}$
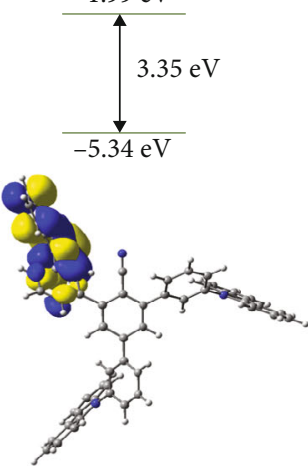

(b)
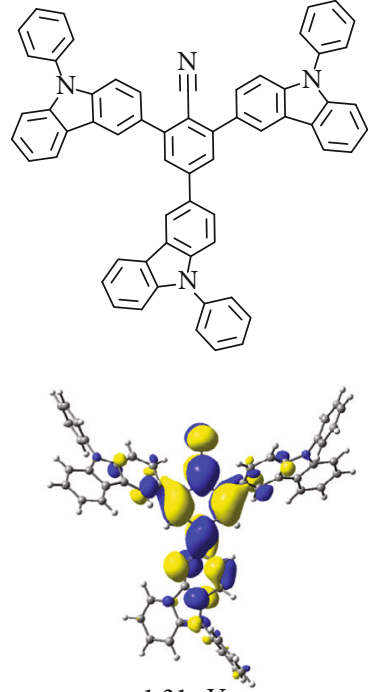

$-1.31 \mathrm{eV}$
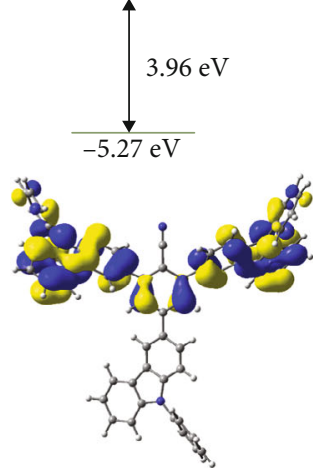

(c)

FIGURE 1: Chemical structures, molecular orbital amplitude plots, and theoretical energy levels of (a) 3Cz-Ph-CN, (b) 3Cz-mPh-CN, and (c) 3Ph-Cz-CN calculated by B3LYP/6-31G (d, p).

compared to that of $3 \mathrm{Cz}-\mathrm{mPh}-\mathrm{CN}$ or $3 \mathrm{Ph}-\mathrm{Cz}-\mathrm{CN}$, indicating its relatively larger conjugation. For $3 \mathrm{Cz}-\mathrm{mPh}-\mathrm{CN}$ and $3 \mathrm{Ph}-\mathrm{Cz}-\mathrm{CN}$, the absorption onset values were 356 and $382 \mathrm{~nm}$, respectively. The blue-shifted absorption onset of $3 \mathrm{Cz}-\mathrm{mPh}-\mathrm{CN}$ indicated that the molecule adopting the meta-connection could induce more twisted architecture. Besides, the peak intensity of the bands aroused by ICT transition could also give some information about the intramolecular charge transfer effect. In $3 \mathrm{Cz}-\mathrm{Ph}-\mathrm{CN}$, due to its better conjugation between the periphery carbazole units and the center benzene unit, the charge transfer effect was more obvious than those of $3 \mathrm{Cz}-\mathrm{mPh}-\mathrm{CN}$ and $3 \mathrm{Ph}-\mathrm{Cz}-\mathrm{CN}$.

In solutions, all the luminogens exhibited fluorescence with blue emission. Similar to our previous results [32], the changing of the connection mode from para-linkage to meta-linkage did not alter the emission largely. As shown in Figure 2(a) and Table 1, the emission wavelength of $3 \mathrm{Cz}-\mathrm{Ph}-\mathrm{CN}$ is located at $441 \mathrm{~nm}$. By adopting the metalinkage way, regardless of the reduced conjugation, $3 \mathrm{Cz}-$ $\mathrm{mPh}-\mathrm{CN}$ showed slightly red-shifted emission. However, $3 \mathrm{Ph}-\mathrm{Cz}-\mathrm{CN}$ with carbazole units connected directly at the benzene core showed the obvious blue-shifted emission compared with those of $3 \mathrm{Cz}-\mathrm{Ph}-\mathrm{CN}$ and $3 \mathrm{Cz}-\mathrm{mPh}-\mathrm{CN}$.
This indicates that the connection through 3-position of the carbazole unit was effective to achieve deep-blue emission in this case.

Typically, for organic molecules, $\pi-\pi$ stacking in the film state will make the emission red-shifted. However, as shown in Table 1, the fluorescent spectrum of $3 \mathrm{Cz}-\mathrm{mPh}-\mathrm{CN}$ showed obvious blue-shifted emission compared with that in solution [32]. To understand this result, two factors should be taken into consideration. In the solution state, the polarity of solvent could enhance the intramolecular charge transfer (ICT) effect, which will make the emission red-shifted. However, in the film state, effect caused by polarity of solvent disappeared. This makes the blue-shifted emission reasonable. Another factor that needs to be discussed was the twisted architecture. The highly twisted structure of the molecule inhibited the $\pi-\pi$ stacking in the film state. In other words, the red-shifted emission phenomenon will be less obvious for the molecule with the highly twisted structure. What we observed should be an overall result caused by these two factors.

In the fluorescent spectra of the films, $3 \mathrm{Cz}-\mathrm{mPh}-\mathrm{CN}$ showed slightly blue-shifted emission $(428 \mathrm{~nm})$ compared with that of $3 \mathrm{Cz}-\mathrm{Ph}-\mathrm{CN}(435 \mathrm{~nm})$. No matter the 


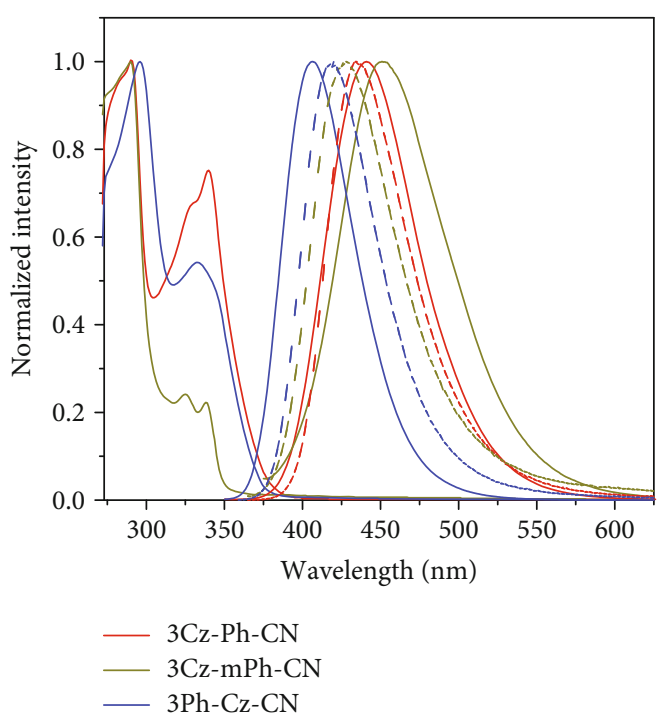

(a)

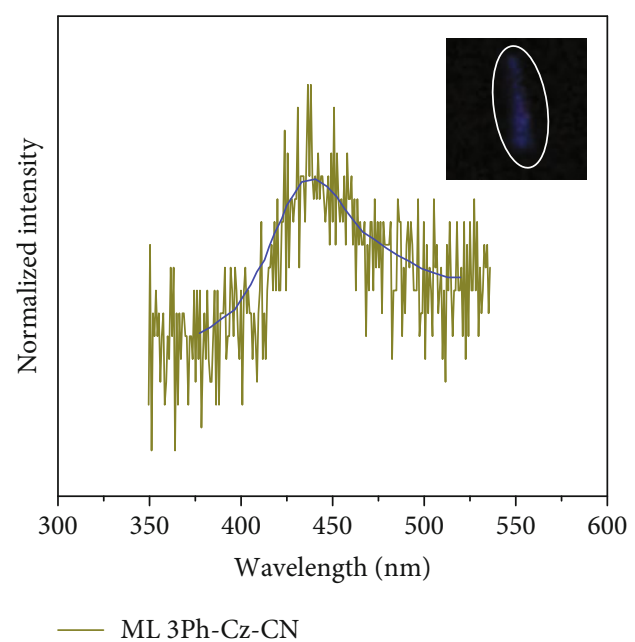

(b)

Figure 2: (a) UV-vis spectra and PL spectra of $3 \mathrm{Cz}-\mathrm{Ph}-\mathrm{CN}$, $3 \mathrm{Cz}-\mathrm{mPh}-\mathrm{CN}$, and $3 \mathrm{Ph}-\mathrm{Cz}-\mathrm{CN}$ in THF solutions $(10 \mu \mathrm{M}$, dotted lines represent the PL spectra of films). (b) Mechanoluminescence spectrum of $3 \mathrm{Ph}-\mathrm{Cz}-\mathrm{CN}$ (inset is the ML image in the dark).

red-shifted emission compared to its solution state, $3 \mathrm{Ph}-\mathrm{Cz}-$ $\mathrm{CN}$ could show deep-blue emission $(420 \mathrm{~nm})$ with narrow fwhm (full width at half-maximum) of $56 \mathrm{~nm}$, which was beneficial for the realization of stable deep-blue emission in OLED devices. In order to quantitatively know the fluorescent properties of these new luminogens, absolute fluorescent quantum yields and fluorescent lifetimes were measured. Benefiting from the highly emissive intramolecular charge transfer (ICT) excited states [20], 3Cz-Ph-CN and 3Ph-Cz$\mathrm{CN}$ showed high fluorescent quantum yields (Table 1). The fluorescent quantum yields of $3 \mathrm{Cz}-\mathrm{Ph}-\mathrm{CN}, 3 \mathrm{Cz}-\mathrm{mPh}-\mathrm{CN}$, and $3 \mathrm{Ph}-\mathrm{Cz}-\mathrm{CN}$ were $90.1 \%, 7.7 \%$, and $65.9 \%$, respectively. With twisted structures and ICT effects inside the luminogens, the possible TADF emission was studied. As shown in Figure 3, all the luminogens exhibited first-order exponential decays with a short fluorescent lifetime (2.35-3.88 ns) in THF solutions, indicating that no thermally activated delayed fluorescence (TADF) emission existed. The absence of TADF emission could also be verified by the energy gap between the lowest singlet state and the lowest triplet state $\left(\Delta E_{\mathrm{st}}\right)$. From the low-temperature fluorescent and phosphorescent spectra (Figure S2), the $\Delta E_{\mathrm{st}}$ values of $3 \mathrm{Cz}-\mathrm{Ph}-\mathrm{CN}, 3 \mathrm{Cz}-$ $\mathrm{mPh}-\mathrm{CN}$, and $3 \mathrm{Ph}-\mathrm{Cz}-\mathrm{CN}$ were calculated to be $0.46,0.50$, and $0.56 \mathrm{eV}$, respectively. According to Adachi's results [17], these values were not small enough to guarantee the efficient reverse intersystem crossing. These results showed that no TADF emission was present to contribute to the intense fluorescent emission and electroluminescent emission in the following parts.

Mechanoluminescence (ML), emission caused by the mechanical force on powders/crystals, has attracted intense interests in recent years $[33,34]$. It was interesting that $3 \mathrm{Ph}-\mathrm{Cz}-\mathrm{CN}$ was ML active. As shown in Figure 2(b), by scratching the powders, deep-blue emission could be observed by naked eyes without irradiation with a UV lamp. According to recent literature results, this unexpected ML property possibly originated from the strong intermolecular interactions [35]. However, regardless of many efforts, the crystal of $3 \mathrm{Ph}-\mathrm{Cz}-\mathrm{CN}$ could not be obtained for the detailed research. However, it is still to be noted that this is the first example of an organic molecule with molecular weight up to $826 \mathrm{~g} / \mathrm{mol}$ possessing the ML property [36]. Also, the previous ML examples exhibited sky-blue to red ML emission, and the cyano-containing ML molecule with a deep-blue ML spectrum $\left(\lambda_{\mathrm{em}}=438 \mathrm{~nm}\right)$ has never been reported. Thus, our case could provide valuable information for the study of ML molecules, and further investigation was required.

2.3. Energy Levels and Theoretic Calculations. To get information about the energy levels, cyclic voltammetry (CV) measurements were carried out (Figure S4). As the hole mobilities of the carbazole-based luminogens were higher than electron mobilities, the highest occupied molecular orbital (HOMO) energy levels of the luminogens were estimated from the onset oxidation potentials according to the equation of $\mathrm{HOMO}=-\left(4.80+E_{\mathrm{ox}}\right) \mathrm{eV}$, while the lowest unoccupied molecular orbital (LUMO) energy levels were calculated by optical band gap energies and HOMO values [30]. As shown in Table 1, the HOMO energy levels for $3 \mathrm{Cz}-\mathrm{Ph}-\mathrm{CN}, \quad 3 \mathrm{Cz}-\mathrm{mPh}-\mathrm{CN}$, and $3 \mathrm{Ph}-\mathrm{Cz}-\mathrm{CN}$ are similarly located at around $-5.60 \mathrm{eV}$. Since the HOMO energy level of NPB, the traditional hole-transporting layer material, is $-5.30 \mathrm{eV}$, these new luminogens could act as light-emitting layers in OLED devices. Besides, their corresponding LUMO energy levels were calculated to be $-2.38,-2.10$, and $-2.37 \mathrm{eV}$, respectively. As the LUMO level of traditional electron-transporting material TPBi is about $-2.7 \mathrm{eV}$, the transfer of electrons would be easy from the TPBi layer to the light-emitting layer in $3 \mathrm{Cz}-\mathrm{Ph}-\mathrm{CN} / 3 \mathrm{Ph}-$ $\mathrm{Cz}-\mathrm{CN}$-based OLED devices. Moreover, the large band gap of $3 \mathrm{Cz}-\mathrm{Ph}-\mathrm{CN}(3.48 \mathrm{eV})$ compared to other carbazolebased emitters indicated its poor conjugation and weak ICT effect, owing to the more twisted structure $[8,32]$.

Calculated by B3LYP/6-31G (d, p), molecular orbital amplitude plots and theoretical energy levels of the three 
TABLE 1: Thermal, electrochemical, and photophysical data of the luminogens.

\begin{tabular}{|c|c|c|c|c|c|c|c|c|c|c|c|}
\hline & \multirow[b]{2}{*}{$T_{\mathrm{d}}{ }^{\mathrm{a}}\left({ }^{\circ} \mathrm{C}\right)$} & \multirow[b]{2}{*}{$T_{\mathrm{g}}^{\mathrm{b}}\left({ }^{\circ} \mathrm{C}\right)$} & \multirow[b]{2}{*}{$E_{\mathrm{g}}{ }^{\mathrm{c}}(\mathrm{eV})$} & \multirow[b]{2}{*}{$E_{\text {HOMO }}{ }^{\mathrm{d}}(\mathrm{eV})$} & \multirow[b]{2}{*}{$E_{\text {LUMO }}{ }^{\mathrm{e}}(\mathrm{eV})$} & \multicolumn{2}{|c|}{ PL $\lambda_{\mathrm{em}}$} & \multirow{2}{*}{$\begin{array}{c}\lambda_{\max , a b s} \\
\operatorname{solv}^{f}(\mathrm{~nm})\end{array}$} & \multirow{2}{*}{$\begin{array}{c}\Phi_{\mathrm{F}} \\
\operatorname{solv}^{\mathrm{f}}(\%)\end{array}$} & \multicolumn{2}{|c|}{$\tau_{\text {lifetime }}$} \\
\hline & & & & & & $\operatorname{solv}^{f}(n m)$ & film $^{\mathrm{g}}(\mathrm{nm})$ & & & $\operatorname{solv}^{\text {h }}$ (ns) & film ${ }^{\mathrm{g}}(\mathrm{ns})$ \\
\hline $3 \mathrm{Cz}-\mathrm{Ph}-\mathrm{CN}$ & 550 & 165 & 3.21 & -5.59 & -2.38 & 441 & 435 & 340 & 90.1 & 3.88 & 4.79 \\
\hline $3 \mathrm{Cz}-\mathrm{mPh}-\mathrm{CN}$ & 504 & 121 & 3.48 & -5.58 & -2.10 & 451 & 428 & 324 & 7.7 & 2.83 & 25.03 \\
\hline $3 \mathrm{Ph}-\mathrm{Cz}-\mathrm{CN}$ & 519 & 141 & 3.25 & -5.62 & -2.37 & 406 & 420 & 332 & 65.9 & 2.35 & 3.36 \\
\hline
\end{tabular}

${ }^{\mathrm{a}} 5 \%$ weight loss temperature measured by TGA under $\mathrm{N}_{2} \cdot{ }^{\mathrm{b}}$ Glass transition temperature measured by DSC under $\mathrm{N}_{2}$. ${ }^{\mathrm{c}}$ Band gap estimated from optical absorption band edge of the solution. ${ }^{\mathrm{d} C a l c u l a t e d}$ from the onset oxidation potentials of the compounds. ${ }^{\mathrm{e}}$ Estimated using empirical equations $E_{\mathrm{LUMO}}=$ $E_{\text {HOMO }}+E_{\mathrm{g}} .{ }^{\mathrm{f}}$ Determined in THF solution. ${ }^{\mathrm{g}}$ On glass. ${ }^{\mathrm{h}}$ Observed from absorption spectra in dilute THF solution, $10 \mu \mathrm{M}$.

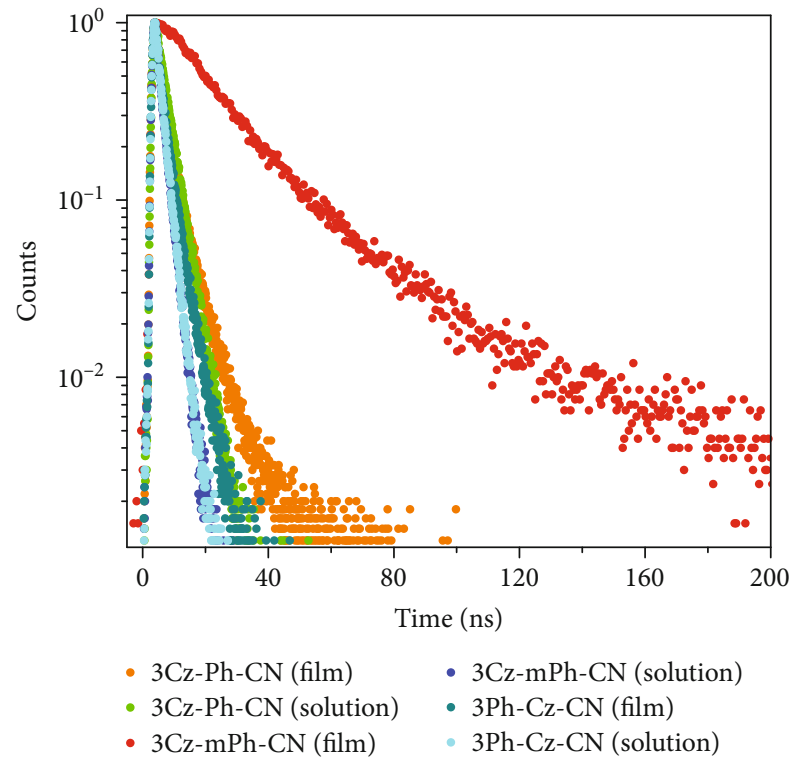

FIGURE 3: Emission decay characteristics of the three luminogens (film and solution states) at room temperature.

luminogens were shown in Figure 1. Like other molecules with electron-donors and electron-acceptors, electron clouds in the HOMOs are mainly located on the carbazole units while those in LUMOs were mainly at the center benzene units. In the three luminogens, there were slight overlaps between the HOMOs and LUMOs, which could be beneficial for the transfer of both electrons and holes when applied in OLED devices $[8,31]$. In the optimized structures, twist angles between the substitution units (ortho-position of the cyano group) and the central benzene were larger than those between the substitution units (para-position of the cyano group) and the central benzene, indicating that the cyano group benefited to the twisting conformation inside luminogens. Actually, the cyano groups were critical for the inhibition of the aggregation-induced quenching (ACQ) effect and the increase of the quantum yields in solid states. Besides, the twist angles between the cyano group and the ortho-substitution units were $49.03,52.74$, and 51.41 for $3 \mathrm{Cz}-\mathrm{Ph}-\mathrm{CN}, 3 \mathrm{Cz}-\mathrm{mPh}-\mathrm{CN}$, and $3 \mathrm{Ph}-\mathrm{Cz}-\mathrm{CN}$, respectively, indicating that the construction of molecules through the meta-linkage approach was an efficient method to make molecules twist.
2.4. Characterization of Nondoped Devices. Prior to the fabrication of OLED devices, hole-only devices with the typical configuration of ITO/ $/ \mathrm{MoO}_{3}(10 \mathrm{~nm}) / \mathrm{X}(15 \mathrm{~nm}) / \mathrm{MoO}_{3}$ $(10 \mathrm{~nm}) / \mathrm{Al}$ were fabricated to evaluate the hole-transporting ability of the carbazole-based luminogens, in which $\mathrm{MoO}_{3}$ layers functioned as both hole-injection and electronblocking layers and $\mathrm{X}$ referred to the newly synthesized luminogens of $3 \mathrm{Cz}-\mathrm{Ph}-\mathrm{CN}, 3 \mathrm{Cz}-\mathrm{mPh}-\mathrm{CN}$, or $3 \mathrm{Ph}-\mathrm{Cz}-\mathrm{CN}$. As shown in Figure 4, the current density-voltage $(J-V)$ profiles indicated that all the three new luminogens exhibited good hole-transport ability [37]. Among them, $3 \mathrm{Cz}-\mathrm{Ph}-\mathrm{CN}$ with the para-linkage mode demonstrated superior holetransport ability. Even though $3 \mathrm{Cz}-\mathrm{mPh}-\mathrm{CN}$ and $3 \mathrm{Ph}-\mathrm{Cz}-$ $\mathrm{CN}$ both possessed twisted architecture, the better transport ability of $3 \mathrm{Ph}-\mathrm{Cz}-\mathrm{CN}$ indicated that the connection through 3-position of the carbazole unit was beneficial for achieving better transport ability while maintaining the twisted structure.

After the survey of hole-only devices, nondoped fluorescent OLED devices were fabricated with the configuration of $\mathrm{ITO} / \mathrm{MoO}_{3}(10 \mathrm{~nm}) / \mathrm{NPB}(60 \mathrm{~nm}) / \mathrm{mCP}(15 \mathrm{~nm}) / \mathrm{X}$ $(30 \mathrm{~nm}) / \mathrm{TPBi}(30 \mathrm{~nm}) / \mathrm{LiF}(1 \mathrm{~nm}) / \mathrm{Al}$ (Figure 5), in which $\mathrm{MoO}_{3}, \mathrm{NPB}$, and TPBi served as hole-injection, holetransporting, and electron-transporting layers. Due to the high triplet state energy $\left(E_{\mathrm{T}}\right)$, the applied neat film of $\mathrm{mCP}$ had been proved to have the ability of confining excitons in the emitting layer (EML) [8]. As shown in Figure 5 and Table 2, all the fabricated devices exhibited blue to deepblue emission as expected. For $3 \mathrm{Cz}-\mathrm{Ph}-\mathrm{CN}$ and $3 \mathrm{Cz}-\mathrm{mPh}-$ $\mathrm{CN}$, the highest external quantum yields (EQEs) were $2.45 \%$ and $1.14 \%$, respectively. The high turn-on voltage $\left(V_{\text {on }}\right)$ gave some clues that the device structures could be further optimized. For the $3 \mathrm{Ph}-\mathrm{Cz}-\mathrm{CN}$-based devices, it was quite shocking that the EQE value could be as high as $18.1 \%$.

Generally, the theoretically determined maximum quantum yield for fluorescent OLEDs could be expressed by the following equation $[38,39]$ :

$$
\eta_{\mathrm{ext}}=\eta_{\text {int }} \times \eta_{\text {out }}=\left(\gamma \times \eta_{\mathrm{ST}} \times \Phi_{\mathrm{PL}}\right) \times \eta_{\text {out }}
$$

where the external quantum efficiency $\left(\eta_{\text {ext }}\right)$ is determined by the internal quantum efficiency $\left(\eta_{\text {int }}\right)$ and light outcoupling factor $\left(\eta_{\text {out }}\right.$, typically $\left.0.2-0.3\right) . \eta_{\text {int }}$ is determined by the charge balance factor $(\gamma$, ideally 1.0 when carriers inside the device were fully balanced), fraction of radiative excitons $\left(\eta_{\mathrm{ST}}, 0.25\right.$ for typical fluorescent emitters) and PL quantum yield of 


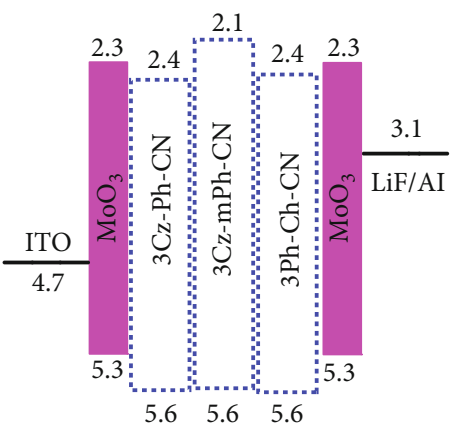

(a)

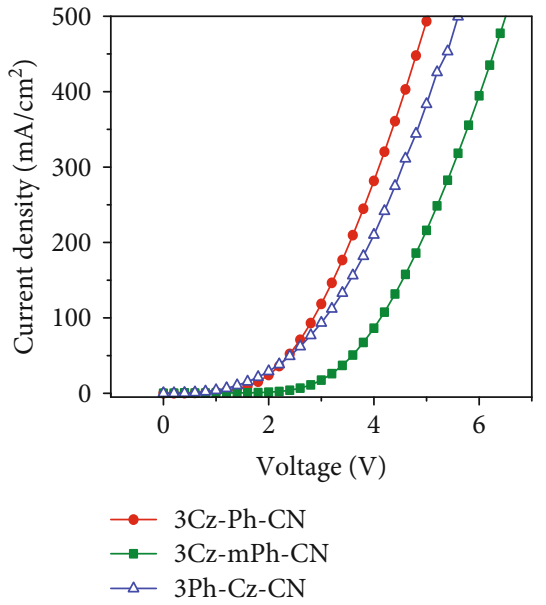

(b)

FIGURE 4: (a) Device structures and (b) current density-voltage profiles of hole-only devices based on the three luminogens.

the emitting layer $\left(\Phi_{\mathrm{PL}}\right)$. In our case, as the value of $\Phi_{\mathrm{PL}}($ film state) was determined to be $41.4 \%$, the theoretical calculated external quantum efficiency should be $2.1-3.1 \%$. However, the actual external quantum efficiency was obviously higher (6-9 times) than the calculated one, unambiguously indicating that some other processes were involved.

With the low $V_{\text {on }}$ value $(2.8 \mathrm{~V})$, the device demonstrated excellent efficiencies with the maximum power efficiency (PE) of $24.9 \mathrm{~lm} \mathrm{~W}^{-1}$ and current efficiency (CE) of $23.8 \mathrm{~cd}$ $\mathrm{A}^{-1}$. According to the emission data summarized in Table 1 , $3 \mathrm{Ph}-\mathrm{Cz}-\mathrm{CN}$ with the highly twisted structure should demonstrate a blue-shifted emission compared to other luminogens. However, due to the shoulder peak located at $506 \mathrm{~nm}$ (Figure 5(e)), devices based on $3 \mathrm{Ph}-\mathrm{Cz}-\mathrm{CN}$ showed larger $\mathrm{CIE}_{y}$ values. Also, along with slightly blue-shifted characteristics, the intensity of the shoulder peak would decrease when higher voltages were applied. At the voltage of $10 \mathrm{~V}$, the device showed CIE of $(0.18,0.19)$. However, the CIE of $(0.17,0.16)$ was observed when the applied voltage was increased to be $12 \mathrm{~V}$. This made it possible for making the emission color varied through subtly changing the applied voltage. And we suspected that the unprecedented high EQE value should have close relationship with the newly formed shoulder peak in the EL spectrum.

According to the previous results reported in literatures $[22,28,40]$, the newly formed peaks in EL spectra were possibly related to phosphorous emission, exciplex emission, or/and electroplex emission. As the shoulder peak could not be observed in the PL spectrum of the solid film, it should not be caused by phosphorous emission [40]. To get further understanding of the above phenomenon, we tested the fluorescent spectrum of the blend film of $3 \mathrm{Ph}-\mathrm{Cz}-\mathrm{CN}$ and $\mathrm{TPBi}$. As shown in Figure 5(f), the blend film also exhibited an emission peak similar to the neat film of $3 \mathrm{Ph}-\mathrm{Cz}-\mathrm{CN}$. Then, the shoulder peak should not be caused by the reported phenomenon of exciplex emission. Actually, the observed phenomena of increased $\mathrm{CIE}_{y}$ and voltage-related EL spectra were the characteristics of electroplex emission [27]. According to Kalinowski et al.'s model [41], at the interface of
3Ph-Cz-CN (D) and TPBi (A), $\left(\mathrm{D}^{+}\right)$and $\left(\mathrm{A}^{-}\right)$could form two possible configurations: locally excited (LOC) configuration $|A * D\rangle$ and charge transfer $(C T)$ configuration $\left|\mathrm{A}^{-} \mathrm{D}^{+}\right\rangle$. The coefficients of $C_{1}$ and $C_{2}$ determine the extent of mixing between LOC and CT configurations:

$$
\Psi_{\mathrm{EX}}=C_{1}|\mathrm{~A} * \mathrm{D}\rangle+C_{2}\left|\mathrm{~A}^{-} \mathrm{D}^{+}\right\rangle
$$

For a special donor and acceptor, when the gap between LUMO of the acceptor and LUMO of the donor is large, electrons at LUMO of the acceptor can directly cross recombine with the holes at the HOMO of the donor. This procedure produces the CT configuration, accompanied with the electroplex emission [42]. In Song et al.'s case [28], the LUMO gap between 3,3-di(9H-carbazol-9-yl)biphenyl (mCBP) and 2,8-bis(4,6-diphenyl-1,3,5-triazin-2-yl)dibenzo[b,d]furan (DBFTrz) was around $0.5 \mathrm{eV}$. However, here, for $3 \mathrm{Ph}-\mathrm{Cz}-\mathrm{CN}$ and TPBi, the electron at the LUMO of TPBi could directly cross recombine with the holes at the HOMO of $3 \mathrm{Ph}-\mathrm{Cz}-$ $\mathrm{CN}$ even though the LUMO gap was just $0.3 \mathrm{eV}$. This case could provide more information for the deep understanding of the formation of electroplex emission. Based on the above analysis, there is no doubt that the CT configuration contributed to the high efficiency of OLED devices. To the best of our knowledge, this is the first example, which achieved unprecedented $\mathrm{EQE}$ value up to $18.1 \%$ in nondoped blue organic light-emitting diodes by utilizing electroplex emission $[28,29]$.

To know more about the emissive properties of electroplex emission, we also carried out transient EL experiments. Figure S7 showed the EL spectra when different voltages were applied. For the emission located around $410 \mathrm{~nm}$, the transient EL spectra exhibited obvious overshoot which declined when higher voltage was applied. Combining with literature reports [43], the overshoot was caused by built-in voltage created by accumulated carriers. When higher voltage was applied, there were more traps in the emitter. And the carriers accumulated in the interface would easily recombine with the traps. This reduced the effect of build- 
<smiles>c1cc(-n2c3ccccc3c3ccccc32)cc(-n2c3ccccc3c3ccccc32)c1</smiles>

$\mathrm{mCP}$

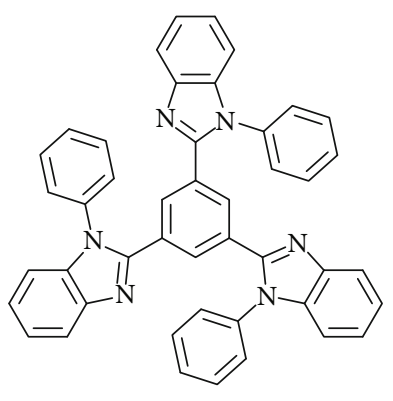

TPBi

(a)

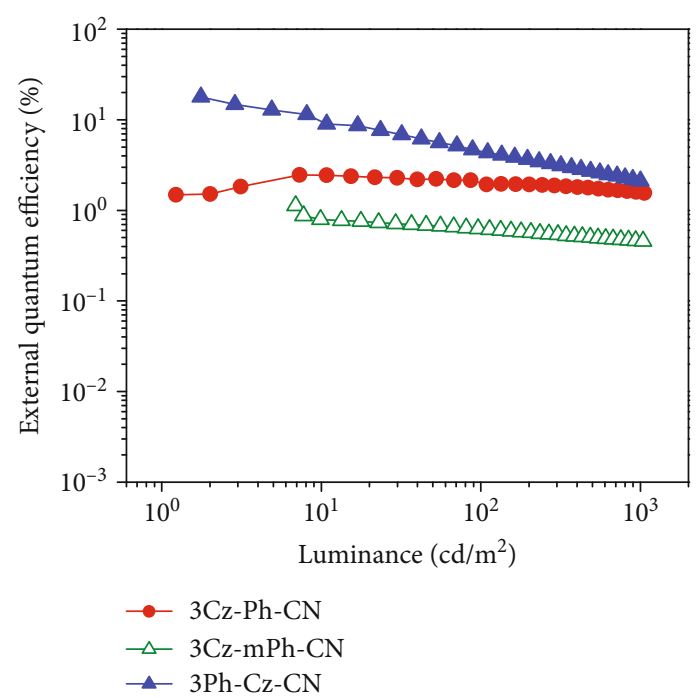

(c)

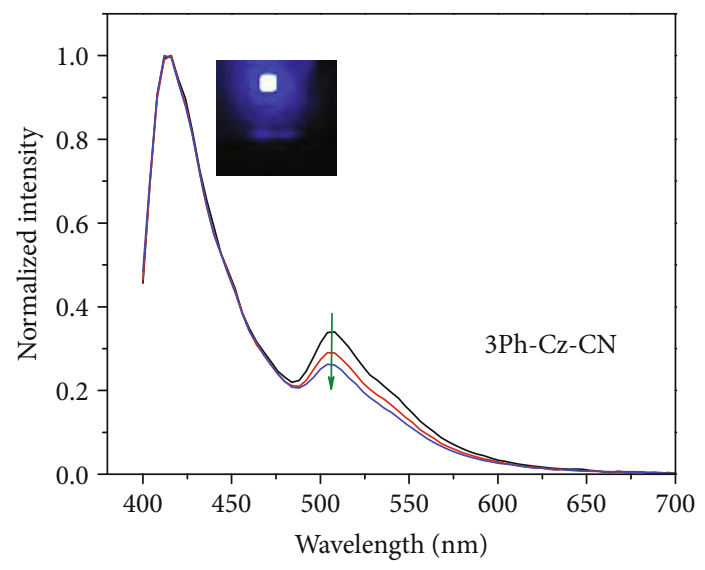

- $10 \mathrm{~V}(0.18,0.19)$

$-11 \mathrm{~V}(0.18,0.17)$

$-12 \mathrm{~V}(0.17,0.16)$

(e)

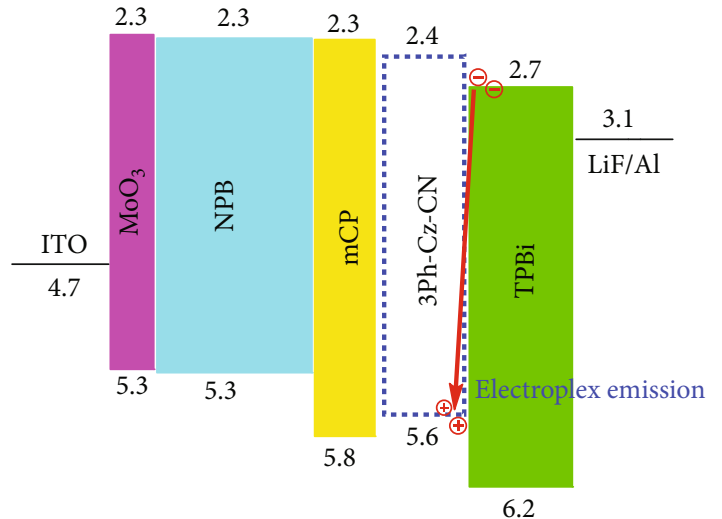

(b)

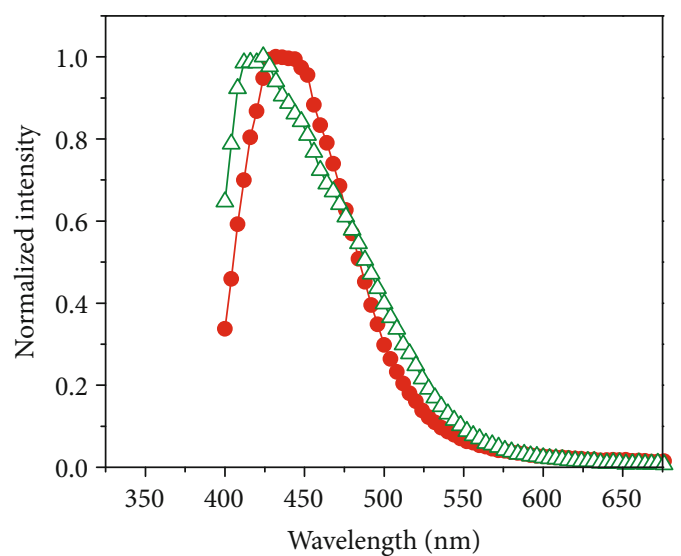

- $3 \mathrm{Cz}-\mathrm{Ph}-\mathrm{CN}$

$\triangle$ 3Cz-mPh-CN

(d)

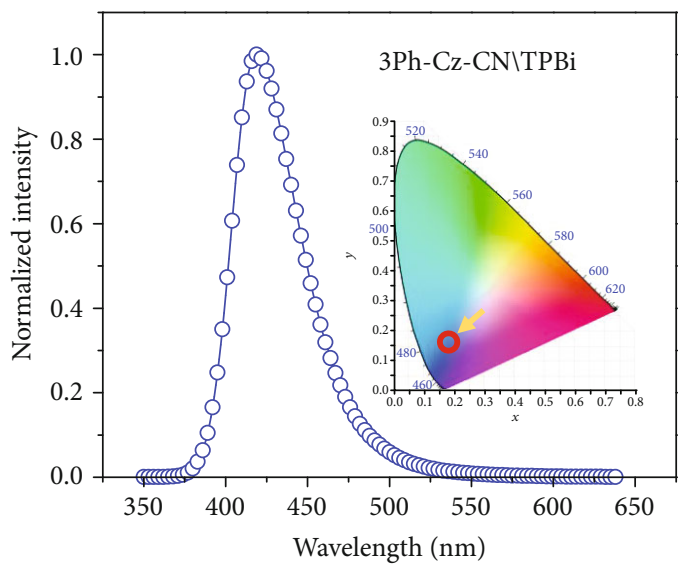

(f)

Figure 5: (a) Chemical structures of $\mathrm{mCP}$ and TPBi. (b) Energy level of nondoped devices with electroplex emission. Device configurations: $\mathrm{ITO} / \mathrm{MoO}_{3}(10 \mathrm{~nm}) / \mathrm{NPB}(60 \mathrm{~nm}) / \mathrm{mCP}(15 \mathrm{~nm}) / \mathrm{EML}(30 \mathrm{~nm}) / \mathrm{TPBi}(30 \mathrm{~nm}) / \mathrm{LiF}(1 \mathrm{~nm}) / \mathrm{Al}$. (c) External quantum efficiency-luminance characteristics of the nondoped devices. (d) EL spectra of $3 \mathrm{Cz}-\mathrm{Ph}-\mathrm{CN}$ and $3 \mathrm{Cz}-\mathrm{mPh}-\mathrm{CN}$. (e) EL spectra of $3 \mathrm{Ph}-\mathrm{Cz}-\mathrm{CN}$ at different voltages (inset is the picture of device $\mathrm{C}$ at the voltage of $12 \mathrm{~V}$ ). (f) PL spectrum of the blend film (inset is the description of CIE in the nondoped device $\mathrm{C}$ ). 
TABLE 2: EL performances of 3Cz-Ph-CN (A/D/G), 3Cz-mPh-CN (B/E/H), and 3Ph-Cz-CN $(\mathrm{C} / \mathrm{F} / \mathrm{I})^{\mathrm{a}}$.

\begin{tabular}{|c|c|c|c|c|c|c|c|}
\hline Device & $\lambda_{\mathrm{EL}}(\mathrm{nm})$ & $V_{\text {on }}(\mathrm{V})$ & $L_{\max }\left(\mathrm{cd} \mathrm{m}^{-2}\right)$ & $\eta_{\mathrm{P}, \max }\left(\operatorname{lm~\mathrm {W}^{-1})}\right.$ & $\eta_{c, \text { max }}\left(\mathrm{cd} \mathrm{A}^{-1}\right)$ & $\eta_{\text {ext,max }}(\%)$ & $\operatorname{CIE}^{\mathrm{b}}(x, y)$ \\
\hline A & 439 & 4.2 & 5304 & 1.37 & 2.24 & 2.45 & $0.16,0.10$ \\
\hline B & 421 & 6.8 & 3057 & 0.45 & 1.09 & 1.14 & $0.16,0.12$ \\
\hline $\mathrm{C}$ & $414(506)$ & 2.8 & 6651 & 24.9 & 23.8 & 18.1 & $0.17,0.16$ \\
\hline $\mathrm{D}$ & 434 & 3.8 & 4518 & 1.32 & 1.76 & 2.94 & $0.16,0.06$ \\
\hline $\mathrm{E}$ & 429 & 5.4 & 1153 & 0.19 & 0.50 & 0.58 & $0.19,0.12$ \\
\hline $\mathrm{F}$ & 420 & 3.2 & 3209 & 1.06 & 1.15 & 1.96 & $0.19,0.12$ \\
\hline G & 562 & 3.4 & 46154 & 59.7 & 80.6 & 26.1 & $0.49,0.50$ \\
\hline $\mathrm{H}$ & 564 & 3.8 & 46401 & 56.6 & 77.2 & 25.1 & $0.49,0.50$ \\
\hline I & 562 & 2.8 & 47952 & 84.5 & 84.6 & 27.4 & $0.49,0.51$ \\
\hline$J^{c}$ & 564 & 2.8 & 48434 & 52.0 & 57.4 & 18.2 & $0.50,0.50[31]$ \\
\hline K & 562 & 3.2 & 47567 & 41.7 & 50.6 & 15.7 & $0.49,0.51[31]$ \\
\hline $\mathrm{L}$ & - & 2.8 & - & 64.5 & - & 24.5 & $0.51,0.49[44]$ \\
\hline M & - & 2.4 & - & 62.1 & - & 25.0 & $0.49,0.49[23]$ \\
\hline
\end{tabular}

${ }^{\mathrm{a} D}$ Device configuration: ITO/MoO $3(10 \mathrm{~nm}) / \mathrm{X} / \mathrm{LiF}(1 \mathrm{~nm}) / \mathrm{Al}$. For devices A-C: X = NPB $(60 \mathrm{~nm}) / \mathrm{mCP}(15 \mathrm{~nm}) / \mathrm{emitter}(30 \mathrm{~nm}) / \mathrm{TPBi}(30 \mathrm{~nm})$. For devices D-F: $\mathrm{X}=\operatorname{emitter}(60 \mathrm{~nm}) / \mathrm{TPBi}(30 \mathrm{~nm})$. For devices G-I: X=NPB $(60 \mathrm{~nm}) / \mathrm{mCP}(10 \mathrm{~nm}) / \mathrm{emitter}: \mathrm{PO}-01 \quad(20 \mathrm{~nm}, 10 \mathrm{wt} \%) / \mathrm{Bphen}(40 \mathrm{~nm}) .{ }^{\mathrm{b}} \mathrm{Abbreviations}$ : $V_{\text {on }}=$ turn-on voltage at $1 \mathrm{~cd} \mathrm{~m}^{-2} ; L_{\max }=$ maximum luminance; $\eta_{\mathrm{p}, \max }, \eta_{c, \max }$, and $\eta_{\mathrm{ext} \text { max }}=$ maximum power, current, and external quantum efficiencies, respectively; $\mathrm{CIE}=$ Commission International de l'Éclairage coordinates. ${ }^{\mathrm{c}}$ Devices J-M: literature results for comparison.

in voltage, and thus, the overshoot diminished. However, for the electroplex emission around $510 \mathrm{~nm}$, the transient EL spectra were almost identical when different voltages were applied. We anticipated that the electroplex located at the interface of the emitter and EML could be weakly influenced by the traps in the emitter. Comparing the transient spectra at different wavelengths, we could draw the conclusion that the lifetime of electroplex emission was longer than that of the fluorescent emission $(410 \mathrm{~nm})$. And when higher voltage was applied, the lifetime of electroplex emission showed an increased trend.

Considering the excellent hole-transporting ability of the three luminogens, we wondered whether the device structures could be simplified by removing the hole-transporting layer (NPB) and exciton-confining layer (mCP) [31]. Then, devices with the configuration of $\mathrm{ITO} / \mathrm{MoO}_{3}(10 \mathrm{~nm}) / \mathrm{X}$ $(60 \mathrm{~nm}) / \mathrm{TPBi} \quad(30 \mathrm{~nm}) / \mathrm{LiF} \quad(1 \mathrm{~nm}) / \mathrm{Al}$ were fabricated (Figure S7). As shown in Figure S7 and Table 2, the CIE and EQE were slightly improved for the devices employing $3 \mathrm{Cz}-\mathrm{Ph}-\mathrm{CN}$-based devices. But for $3 \mathrm{Cz}-\mathrm{mPh}-\mathrm{CN}$ and $3 \mathrm{Ph}-$ $\mathrm{Cz}-\mathrm{CN}$, perhaps, the hole-transporting abilities were not high enough for the possibilities of removing holetransporting layers. Besides, in the $3 \mathrm{Ph}-\mathrm{Cz}-\mathrm{CN}$-based devices, the electroplex emission could not be observed, demonstrating that the properly designed device structure should also be critical for the utilization of electroplex emission.

2.5. Characterization of Doped Devices. CN-containing luminogens had been reported to be used as efficient host material in OLED devices $[31,44]$. Considering the triplet energy level, doped devices with the configuration of $\mathrm{ITO} / \mathrm{MoO}_{3}$ $(10 \mathrm{~nm}) / \mathrm{NPB} \quad(60 \mathrm{~nm}) / \mathrm{mCP} \quad(10 \mathrm{~nm}) / \mathrm{X}: \mathrm{PO}-01 \quad(20 \mathrm{~nm}$, $10 \mathrm{wt} \%) /$ Bphen $(40 \mathrm{~nm}) / \mathrm{LiF}(1 \mathrm{~nm}) / \mathrm{Al}$ were fabricated, in which Bphen (bathophenanthroline) was used as the electron-transporting layer (Figure 6, devices G-I). All the fabricated devices demonstrated stable orange emission with high efficiencies. For 3Cz-mPh-CN-based doped devices, $V_{\text {on }}$ and maximum luminance $\left(L_{\max }\right)$ was $3.8 \mathrm{~V}$ and $46401 \mathrm{~cd} \mathrm{~m}^{-2}$, respectively. The EL spectra were almost unchanged when different voltages were applied. With the EL spectrum located at $564 \mathrm{~nm}$, the external quantum efficiency could be as high as $25.1 \%$. For $3 \mathrm{Cz}-\mathrm{Ph}-\mathrm{CN}, V_{\text {on }}$ was reduced to be $3.4 \mathrm{~V}$, indicating the improved matching of energy levels [45]. As the result, the device demonstrated improved performance with EQE of $26.1 \%$. It is interesting that for the device I employing $3 \mathrm{Ph}-\mathrm{Cz}-\mathrm{CN}$ as the host material, unprecedented high EQE of $27.4 \%$ could be achieved. It was worth noting that this was the highest external quantum efficiency for the PO-01based phosphorous OLED [23, 31, 44]. For the detailed parameters, $V_{\text {on }}$ could be decreased to be as low as $2.8 \mathrm{~V}$, indicating the easier transfer of carriers inside the fabricated device. With improved luminance $\left(47952 \mathrm{~cd} \mathrm{~m}^{-2}\right)$, the device exhibited maximum $\mathrm{PE}$ and $\mathrm{CE}$ of $84.5 \mathrm{~cd} \mathrm{~m}^{-2}$ and $84.6 \mathrm{~cd}$ $\mathrm{A}^{-1}$, respectively. From the characteristics in Figure 6(c) and Figure 6(d), device I demonstrated excellent stability and low efficiency roll-off. In particular, at the luminance of $1000 \mathrm{~cd} \mathrm{~m}^{-2}$, maximum CE and EQE of the doped device could still remain $70.3 \mathrm{~cd} \mathrm{~m}^{-2}$ and $22.2 \%$, respectively. All the results demonstrated that the easily synthesized luminogens could be an excellent host for orange emission. Benefit from the donor-acceptor structures and good transport abilities, the high efficiencies, and small roll-off indicated that triplet-triplet annihilation and exciton-polaron annihilation inside the devices were efficiently inhibited [46]. However, compared with the other two hosts, the $3 \mathrm{Cz}-\mathrm{mPh}-\mathrm{CN}$-based device exhibited relatively lower efficiency and higher $V_{\text {on }}$ value (Table 2 ). This was mainly attributed to the relatively larger LUMO gap between $3 \mathrm{Cz}-\mathrm{mPh}-\mathrm{CN}$ and Bphen (Figure S11). When utilized as host materials, regardless of 


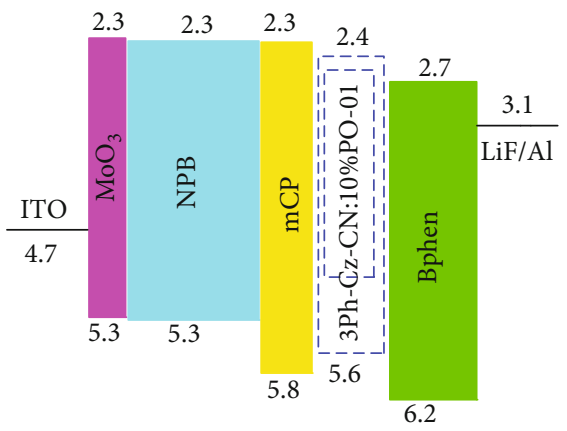

(a)

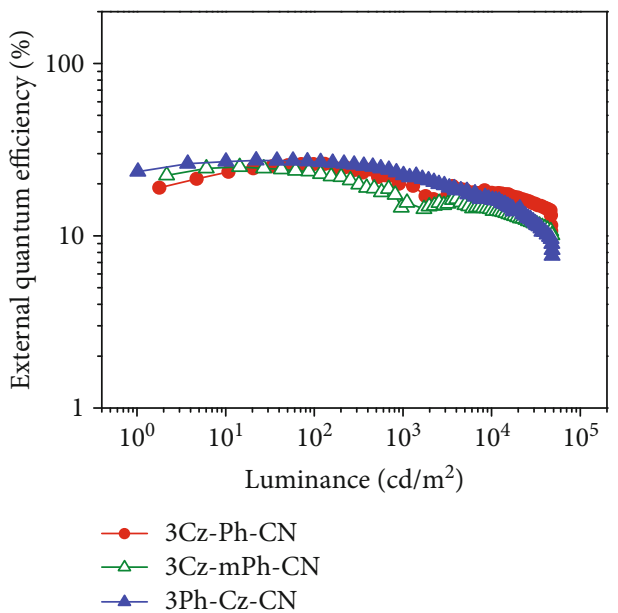

(c)

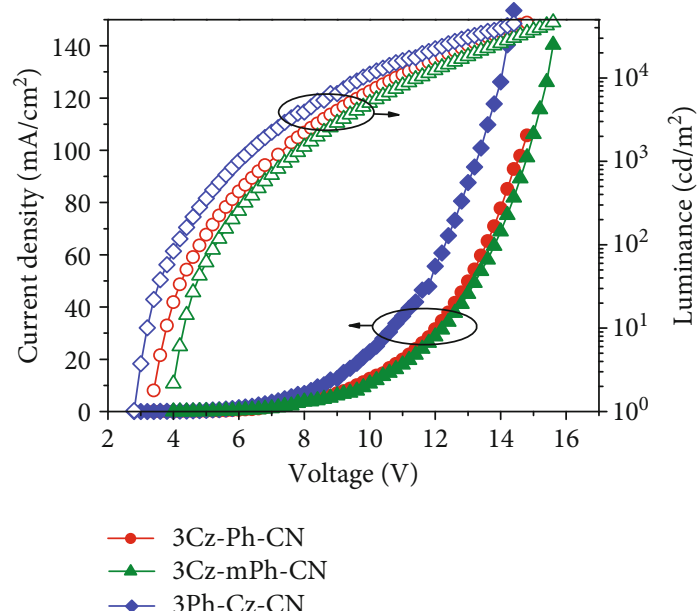

(b)

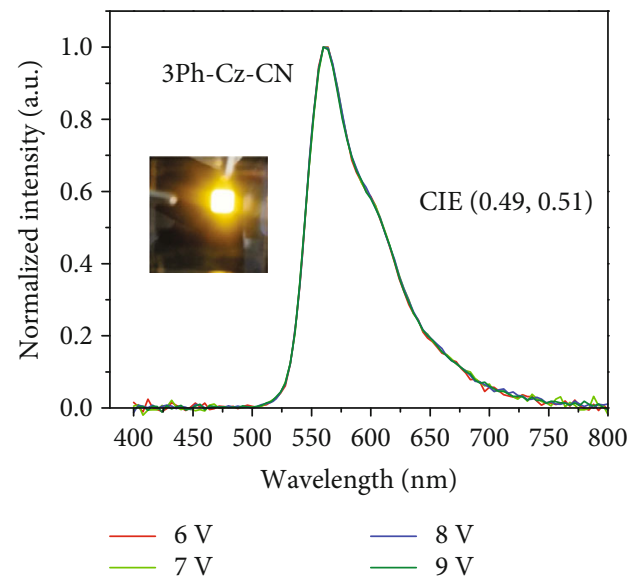

(d)

Figure 6: (a) Energy level of doped devices. (b) Current density-voltage-luminance characteristics and (c) change in external quantum efficiency with the luminance in the doped devices. (d) EL spectrum of $3 \mathrm{Ph}-\mathrm{Cz}-\mathrm{CN}$ at different voltages in device I (inset is the picture of device I at the voltage of $8 \mathrm{~V})$. Device configurations: ITO/MoO $3(10 \mathrm{~nm}) / \mathrm{NPB}(60 \mathrm{~nm}) / \mathrm{mCP}(10 \mathrm{~nm}) / \mathrm{X}: \mathrm{PO}-01(20 \mathrm{~nm}, 10 \mathrm{wt} \%) / \mathrm{Bphen}$ $(40 \mathrm{~nm}) / \mathrm{LiF}(1 \mathrm{~nm}) / \mathrm{Al}$.

similar HOMO/LUMO energy levels and triplet energy levels, 3Ph-Cz-CN with relatively poor hole-transport ability exhibited better device performance than that of $3 \mathrm{Cz}-\mathrm{Ph}-\mathrm{CN}$. Because of the hole-dominated transport property $[18,29,42]$, the reason could be attributed to the more balanced carrier transfer inside the $3 \mathrm{Ph}-\mathrm{Cz}-\mathrm{CN}$-based device [46]. Another reason could be attributed to the relatively strong intermolecular $\pi-\pi$ stacking in the $3 \mathrm{Cz}-\mathrm{Ph}$ $\mathrm{CN}$ films, which was not beneficial for the inhibition of concentration quenching [47]. Adversely, the larger twisting degree inside $3 \mathrm{Ph}-\mathrm{Cz}-\mathrm{CN}$ benefited for the maintenance of the amorphous state.

\section{Discussion}

In summary, luminogens with good stability and robust emission were synthesized through simple procedures. By utilizing the electroplex emission, TADF-absent luminogen of $3 \mathrm{Ph}-\mathrm{Cz}-\mathrm{CN}$ exhibited the unprecedented high external quantum efficiency of $18.1 \%$ in nondoped devices, providing a new possibility to greatly enhance the performance for OLEDs with blue emissions. Furthermore, orange-emitting PhOLEDs employing $3 \mathrm{Ph}-\mathrm{Cz}-\mathrm{CN}$ as host material provided the maximum $\mathrm{CE}$ and $\mathrm{EQE}$ of $84.6 \mathrm{~cd} \mathrm{~A}^{-1}$ and $27.4 \%$, respectively, with small efficiency roll-off. The achieved $\mathrm{EQE}$ value is the highest external quantum efficiency for PO-01-based phosphorous OLED up to date. At the luminance of $1000 \mathrm{~cd} \mathrm{~m}^{-2}$, maximum $\mathrm{CE}$ and $\mathrm{EQE}$ of the doped device can still remain $70.3 \mathrm{~cd} \mathrm{~m}^{-2}$ and $22.2 \%$, respectively, confirming the advantages of $3 \mathrm{Ph}-\mathrm{Cz}-\mathrm{CN}$ as host material for orange-emitting PhOLEDs.

\section{Materials and Methods}

4.1. Characterization. ${ }^{1} \mathrm{H}$ and ${ }^{13} \mathrm{C}$ NMR spectra were measured on WNMR-I NMR $(600 \mathrm{MHz})$ and Bruker AVANCE III HD $(400 \mathrm{MHz})$ spectrometers, respectively. Elemental analyses of carbon $(\mathrm{C})$, hydrogen $(\mathrm{H})$, and nitrogen $(\mathrm{N})$ were 
performed on a CARLO ERBA-1106 microanalyzer. The MS (EI) spectrum was recorded on a Finnigan PRACE mass spectrometer. MALDI-TOF spectra were measured with a Bruker Autoflex III mass spectrometer operating in MALDI-TOF (matrix-assisted laser desorption/ionizationtime-of-flight) mode with 1,8,9-anthracenetriol as the matrix. For photophysical properties, UV-vis absorption spectra were recorded on a Shimadzu UV-2500 recording spectrometer while the photoluminescence spectra were recorded on a Hitachi F-4500 fluorescence spectrometer. For low-temperature tests, samples were all cooled in liquid nitrogen. The emission decay profiles were measured with a FLS980 fluorescence lifetime spectrometer. In the atmosphere of nitrogen, thermogravimetric analysis (TGA) and differential scanning calorimetry (DSC) were performed with NETZSCH STA 449C and Mettler Toledo DSC 822e instrument, respectively. Cyclic voltammetry (CV) curves of the three emitters were obtained on a CHI voltammetric analyzer in a three-electrode cell. The three electrodes were the $\mathrm{Pt}$ counter electrode, $\mathrm{Ag} / \mathrm{AgCl}$ reference electrode, and glassy carbon working electrode. The scans were performed at the rate of $100 \mathrm{mV} \mathrm{s}^{-1}$ with tetrabutylammonium perchlorate (0.1 M, anhydrous dichloromethane solution purged with nitrogen) as the supporting electrolyte. All the potential values obtained were converted to values versus the saturated calomel electrode (SCE) by using ferrocenium/ferrocene $\left(\mathrm{Fc}^{+} / \mathrm{Fc}\right)$ as the internal standard. The electronic and geometrical properties of all the three luminogens were optimized by Gaussian 09 program (B3LYP/6-31 g(d) level).

4.2. OLED Device Fabrication and Measurement. Beside light-emitting layers, all the materials were obtained from a commercial source. Before deposition of the organic layer, clean ITO substrates were treated with oxygen plasma for $2 \mathrm{~min}$. EL devices were fabricated by vacuum deposition of the materials at a base pressure of $10^{-6}$ Torr onto glass with a layer of indium tin oxide (ITO) with a sheet resistance of $25 \Omega$ /square. The deposition rate of organic compounds was controlled to be $1-2 \AA \mathrm{s}^{-1}$. Finally, a cathode composed of lithium fluoride ( $\mathrm{LiF}, 1 \mathrm{~nm}$ ) and aluminium (Al, $100 \mathrm{~nm}$ ) was carefully deposited onto the substrate in the vacuum of $10^{-6}$ Torr. The $L-V-J$ characteristics of the fabricated devices were measured with a Keithley 2400 Source meter and a Keithley 2000 Source multimeter equipped with a calibrated silicon photodiode. EL spectra of devices were measured by a JY SPEX CCD3000 spectrometer. All measurements were carried out at room temperature under ambient conditions.

4.2.1. Synthesis of $3 C z-P h-C N$. A mixture of 2,4,6-tribromobenzonitrile (337 mg, $1.0 \mathrm{mmol})$, (4-(9H-carbozol-9-yl)phenyl)boronic acid (1.43 g, $5.0 \mathrm{mmol}), \mathrm{Pd}\left(\mathrm{PPh}_{3}\right)_{4}(50 \mathrm{mg})$ and potassium carbonate $(4.14 \mathrm{~g}, 30 \mathrm{mmol})$ in toluene (35 mL), EtOH $(7.0 \mathrm{~mL})$, and distilled water $(15 \mathrm{~mL})$ was refluxed for $24 \mathrm{~h}$ under nitrogen in a $250 \mathrm{~mL}$ Schlenk tube. After quenching by water, the resultant mixture was extracted with dichloromethane. Then, the combined organic extracts were dried over anhydrous $\mathrm{Na}_{2} \mathrm{SO}_{4}$ and concentrated by rotary evaporation. The crude product was purified by column chromatography on silica gel using dichloromethane/- petroleum ether as eluent to afford the product as light yellow solid in the yield of $56 \%(461 \mathrm{mg}) .{ }^{1} \mathrm{H}$ NMR $(600$ $\left.\mathrm{MHz} \mathrm{CDCl}_{3}\right) \delta$ (ppm): $8.19(\mathrm{~d}, J=7.8 \mathrm{~Hz}, 6 \mathrm{H}), 8.03-7.80$ $(\mathrm{m}, 8 \mathrm{H}), 7.82(\mathrm{~d}, J=7.8 \mathrm{~Hz}, 4 \mathrm{H}), 7.79(\mathrm{~d}, J=7.8 \mathrm{~Hz}, 2 \mathrm{H})$, $7.59(\mathrm{~d}, J=8.4 \mathrm{~Hz}, 4 \mathrm{H}), 7.52-7.46(\mathrm{~m}, 8 \mathrm{H}), 7.35-7.32$ $(\mathrm{m}, 6 \mathrm{H}) .{ }^{13} \mathrm{C} \mathrm{NMR}\left(100 \mathrm{MHz}, \mathrm{CDCl}_{3}\right) \delta(\mathrm{ppm}): 140.6$, $138.6,137.3,130.7,129.0,128.0,127.7,127.2,126.1,123.6$, $120.5,120.4,120.3,109.9,109.7$. MS (MALDI-TOF), m/z: $826.45\left(\left[\mathrm{M}^{+}\right]\right.$, calcd for $\left.\mathrm{C}_{61} \mathrm{H}_{38} \mathrm{~N}_{4}, 826.31\right)$. Anal. Calcd for $\mathrm{C}_{61} \mathrm{H}_{38} \mathrm{~N}_{4}$ : C, 88.59; $\mathrm{H}, 4.63 ; \mathrm{N}, 6.77$. Found: $\mathrm{C}, 88.43 ; \mathrm{H}$, $4.85 ; \mathrm{N}, 6.51$.

4.2.2. Synthesis of $3 C z-m P h-C N$. The synthetic procedure was similar to that of $3 \mathrm{Cz}-\mathrm{Ph}-\mathrm{CN}$. 2,4,6-Tribromobenzonitrile (200 mg, $0.59 \mathrm{mmol})$ reacted with (3-(9H-carbozol-9-yl)phenyl)boronic acid (852 $\mathrm{mg}, 2.97 \mathrm{mmol})$, in the presence of $\mathrm{Pd}\left(\mathrm{PPh}_{3}\right)_{4}(50 \mathrm{mg})$ and potassium carbonate $(2.48 \mathrm{~g}, 18.0$ $\mathrm{mmol}$ ), to yield $3 \mathrm{Cz}-\mathrm{mPh}-\mathrm{CN}$ (white solid, $72 \%, 351 \mathrm{mg}$ ). ${ }^{1} \mathrm{H}$ NMR $\left(600 \mathrm{MHz}, \mathrm{CDCl}_{3}\right) \delta$ (ppm): $8.15(\mathrm{~d}, J=7.8 \mathrm{~Hz}$, $6 \mathrm{H}), 7.86(\mathrm{~s}, 3 \mathrm{H}), 7.82(\mathrm{~s}, 2 \mathrm{H}), 7.78-7.71(\mathrm{~m}, 8 \mathrm{H}), 7.65$ $(\mathrm{d}, J=7.2 \mathrm{~Hz}, 1 \mathrm{H}), 7.59(\mathrm{~d}, J=8.4 \mathrm{~Hz}, 4 \mathrm{H}), 7.43-7.38$ $(\mathrm{m}, 8 \mathrm{H}), 7.31-7.28(\mathrm{~m}, 6 \mathrm{H}) .{ }^{13} \mathrm{C}$ NMR $\left(100 \mathrm{MHz}, \mathrm{CDCl}_{3}\right)$ $\delta$ (ppm): 146.7, 144.4, 140.8, 140.7, 140.2, 138.7, 138.3, $130.9,130.4,128.0,127.9,127.8,127.6,126.5,126.1,123.5$, $123.4,120.5,120.3,120.2,110.0,109.6 . \mathrm{MS}$ (MALDI-TOF), $\mathrm{m} / \mathrm{z}: 826.38\left(\left[\mathrm{M}^{+}\right]\right.$, calcd for $\left.\mathrm{C}_{61} \mathrm{H}_{38} \mathrm{~N}_{4}, 826.31\right)$. Anal. Calcd for $\mathrm{C}_{61} \mathrm{H}_{38} \mathrm{~N}_{4}$ : C, 88.59; H, 4.63; N, 6.77. Found: C, 88.53; $\mathrm{H}, 4.74 ; \mathrm{N}, 6.49$.

4.2.3. Synthesis of $3 \mathrm{Ph}-\mathrm{Cz}-\mathrm{CN}$. The synthetic procedure was similar to that of $3 \mathrm{Cz}-\mathrm{Ph}-\mathrm{CN}$. 2,4,6-Tribromobenzonitrile (200 mg, $0.59 \mathrm{mmol}$ ) reacted with (9-phenyl-9H-carbazol3-yl)boronic acid (852 $\mathrm{mg}, 2.97 \mathrm{mmol}$ ), in the presence of $\mathrm{Pd}\left(\mathrm{PPh}_{3}\right)_{4}(50 \mathrm{mg})$ and potassium carbonate $(2.48 \mathrm{mg}, 18.0$ $\mathrm{mmol}$ ) to yield $3 \mathrm{Ph}-\mathrm{Cz}-\mathrm{CN}$ (white solid, 63\%, $307 \mathrm{mg}$ ). ${ }^{1} \mathrm{H}$ NMR (600 MHz, $\left.\mathrm{CDCl}_{3}\right) \delta(\mathrm{ppm}): 8.54$ (s, 1H), 8.50 (s, 2H), $8.25(\mathrm{~d}, J=7.8 \mathrm{~Hz}, 2 \mathrm{H}), 8.23(\mathrm{~d}, J=7.8 \mathrm{~Hz}, 1 \mathrm{H})$, 7.97 (s, 2H), 7.84-7.81 (m, 3H), 7.65-7.61 (m, 12H), 7.58 $(\mathrm{d}, J=9.0 \mathrm{~Hz}, 2 \mathrm{H}), 7.52-7.45(\mathrm{~m}, 10 \mathrm{H}), 7.34-7.32(\mathrm{~m}, 3 \mathrm{H})$. ${ }^{13} \mathrm{C} \mathrm{NMR}\left(100 \mathrm{MHz}, \mathrm{CDCl}_{3}\right) \delta(\mathrm{ppm}): 148.3,145.7,141.5$, $141.4,141.1,141.0,137.5,137.4,131.4,131.1,130.1,130.0$, $127.7,127.5,127.2,127.1,126.4,123.7,123.4,121.2,120.7$, 120.6, 120.4, 120.3, 119.4, 110.4, 110.1, 110.0, 109.9, 108.8. MS (MALDI-TOF), m/z: $826.41\left(\left[\mathrm{M}^{+}\right]\right.$, calcd for $\mathrm{C}_{61} \mathrm{H}_{38} \mathrm{~N}_{4}$, 826.31). Anal. Calcd for $\mathrm{C}_{61} \mathrm{H}_{38} \mathrm{~N}_{4}$ : C, 88.59; $\mathrm{H}, 4.63 ; \mathrm{N}$, 6.77. Found: C, $88.55 ; \mathrm{H}, 4.73 ; \mathrm{N}, 6.54$.

\section{Conflicts of Interest}

The authors declare that there are no conflicts of interest regarding the publication of this article.

\section{Authors' Contributions}

Z.L., Q.L., and X.Z. conceived the project. X.Z., Y.G., and J.T. conducted the synthesis, photophysical characterizations, and design of OLED devices. Z.W. and D.M. did the device fabrication and measurement. Y.X. and Q.P. did the DFT calculations. All authors participated in writing the manuscript. 
Xuejun Zhan and Zhongbin $\mathrm{Wu}$ contributed equally to this work.

\section{Acknowledgments}

We are grateful to the National Science Foundation of China (nos. 21734007, 51573140, 91833304, and 11661131001), Fundamental Research Funds for the Central Universities (2042017kf0247), and Hubei Province (2017CFA002) for financial support.

\section{Supplementary Materials}

Chart S1: representative blue luminogens designed by our group (note: the EQE values could not surpass 5\% due to their pure fluorescent emissions). Scheme S1: detailed synthetic routes of the three luminogens. Figure S1: TGA and DSC curves of the cyano-based luminogens recorded under $\mathrm{N}_{2}$. Figure S2: normalized fluorescence and phosphorescence spectra of $3 \mathrm{Cz}-\mathrm{Ph}-\mathrm{CN}, 3 \mathrm{Cz}-\mathrm{mPh}-\mathrm{CN}$, and $3 \mathrm{Ph}-\mathrm{Cz}-\mathrm{CN}$ at $77 \mathrm{~K}$ in a frozen 2-methyl-THF matrix. Concentration: 10-3 M. Figure S3: fluorescence and phosphorescence spectra of $3 \mathrm{Cz}-\mathrm{Ph}-\mathrm{CN}, 3 \mathrm{Cz}-\mathrm{mPh}-\mathrm{CN}$, and $3 \mathrm{Ph}-\mathrm{Cz}-\mathrm{CN}$ at $77 \mathrm{~K}$ in a frozen 2-methyl-THF matrix. Concentration: $10-3 \mathrm{M}$. Figure S4: cyclic voltammograms of the three luminogens recorded in dichloromethane. Figure S5: (a) current density-voltage-luminance characteristics, (b) current efficiency-luminance characteristics, and (c) power efficiency-luminance characteristics of the nondoped devices. Device configurations: ITO/ $\mathrm{MoO}_{3}(10 \mathrm{~nm}) / \mathrm{NPB}$ $(60 \mathrm{~nm}) / \mathrm{mCP}(15 \mathrm{~nm}) / \mathrm{X}(30 \mathrm{~nm}) / \mathrm{TPBi}(30 \mathrm{~nm}) / \mathrm{LiF}(1 \mathrm{~nm}) /$ $\mathrm{Al}$; X refers to $3 \mathrm{Cz}-\mathrm{Ph}-\mathrm{CN}$ or $3 \mathrm{Cz}-\mathrm{mPh}-\mathrm{CN}$ or $3 \mathrm{Ph}-\mathrm{Cz}-\mathrm{CN}$. Figure S6: EL spectra of (a) $3 \mathrm{Cz}-\mathrm{Ph}-\mathrm{CN}$, (b) $3 \mathrm{Cz}-\mathrm{mPh}-\mathrm{CN}$, and (c) $3 \mathrm{Ph}-\mathrm{Cz}-\mathrm{CN}$ in the nondoped devices. Device configurations: $\mathrm{ITO} / \mathrm{MoO}_{3}(10 \mathrm{~nm}) / \mathrm{NPB}(60 \mathrm{~nm}) / \mathrm{mCP}(15 \mathrm{~nm}) / \mathrm{X}$ $(30 \mathrm{~nm}) / \mathrm{TPBi}(30 \mathrm{~nm}) / \mathrm{LiF}(1 \mathrm{~nm}) / \mathrm{Al} ; \mathrm{X}$ refers to $3 \mathrm{Cz}-\mathrm{Ph}-\mathrm{CN}$ or $3 \mathrm{Cz}-\mathrm{mPh}-\mathrm{CN}$ or $3 \mathrm{Ph}-\mathrm{Cz}-\mathrm{CN}$. Figure $\mathrm{S} 7$ : transient EL spectra of $3 \mathrm{Ph}-\mathrm{Cz}-\mathrm{CN}$ in the nondoped devices. Device configurations: $\mathrm{ITO} / \mathrm{MoO}_{3}(10 \mathrm{~nm}) / \mathrm{NPB} \quad(60 \mathrm{~nm}) / \mathrm{mCP} \quad(15 \mathrm{~nm}) / \mathrm{X}$ $(30 \mathrm{~nm}) / \mathrm{TPBi}(30 \mathrm{~nm}) / \mathrm{LiF}(1 \mathrm{~nm}) / \mathrm{Al} ; \mathrm{X}$ refers to $3 \mathrm{Ph}-\mathrm{Cz}-$ $\mathrm{CN}$. Figure S8: current efficiency-luminance characteristics of the devices without hole-transporting layers (NPB). Inset is the diagram of energy levels. Device configurations: ITO/ $\mathrm{MoO}_{3} \quad(10 \mathrm{~nm}) / \mathrm{X} \quad(30 \mathrm{~nm}) / \mathrm{TPBi} \quad(30 \mathrm{~nm}) / \mathrm{LiF} \quad(1 \mathrm{~nm}) / \mathrm{Al}$. Figure S9: (a) current density-voltage-luminance characteristics, (b) external quantum efficiency-luminance characteristics, (c) current efficiency-luminance characteristics, and (d) power efficiency-luminance characteristics of the doped devices. Device configurations: ITO/ $\mathrm{MoO}_{3}(10 \mathrm{~nm}) / \mathrm{NPB}$ $(60 \mathrm{~nm}) / \mathrm{mCP} \quad(10 \mathrm{~nm}) / \mathrm{X}: \mathrm{PO}-01 \quad(20 \mathrm{~nm}, 10 \mathrm{wt} \%) / \mathrm{Bphen}$ $(40 \mathrm{~nm}) / \mathrm{LiF}(1 \mathrm{~nm}) / \mathrm{Al}$. Figure S10: EL spectra of (a) $3 \mathrm{Cz}-$ $\mathrm{Ph}-\mathrm{CN}$, (b) $3 \mathrm{Cz}-\mathrm{mPh}-\mathrm{CN}$, and (c) $3 \mathrm{Ph}-\mathrm{Cz}-\mathrm{CN}$ in the doped devices. Device configurations: $\mathrm{ITO} / \mathrm{MoO}_{3}(10 \mathrm{~nm}) / \mathrm{NPB}$ $(60 \mathrm{~nm}) / \mathrm{mCP} \quad(10 \mathrm{~nm}) / \mathrm{X}: \mathrm{PO}-01 \quad(20 \mathrm{~nm}, 10 \mathrm{wt} \%) /$ Bphen $(40 \mathrm{~nm}) / \mathrm{LiF}(1 \mathrm{~nm}) / \mathrm{Al}$. Figure S11: energy level diagram of the hole-only device (A), nondoped devices $(\mathrm{B} / \mathrm{C})$, and doped device (D). Figures S12-S17: ${ }^{1} \mathrm{H}$ NMR and ${ }^{13} \mathrm{C}$ NMR spectra of the three luminogens in deuterated chloroform. Figures S18-S20: MALDI-TOF mass spectra of the three luminogens. (Supplementary Materials)

\section{References}

[1] C. W. Tang and S. A. Vanslyke, "Organic electroluminescent diodes," Applied Physics Letters, vol. 51, no. 12, pp. 913-915, 1987.

[2] T. Chao, Y.-T. Lin, C.-Y. Yang et al., "Highly efficient UV organic light-emitting devices based on bi(9,9-diarylfluorene)s," Advanced Materials, vol. 17, no. 8, pp. 992-996, 2005.

[3] M. A. McCarthy, B. Liu, E. P. Donoghue et al., "Low-voltage, low-power, organic light-emitting transistors for active matrix displays," Science, vol. 332, no. 6029, pp. 570-573, 2011.

[4] L. Xiao, S. Su, Y. Agata, H. Lan, and J. Kido, "Nearly 100\% internal quantum efficiency in an organic blue-light Electrophosphorescent device using a weak electron transporting material with a wide energy gap," Advanced Materials, vol. 21, no. 12, pp. 1271-1274, 2009.

[5] L. Yao, S. Zhang, R. Wang et al., "Highly efficient near-infrared organic light-emitting diode based on a butterfly-shaped donor-acceptor chromophore with strong solid-state fluorescence and a large proportion of radiative excitons," Angewandte Chemie International Edition, vol. 53, no. 8, pp. 2119-2123, 2014.

[6] P. Gu, Y. Zhao, J.-H. He et al., "Synthesis, physical properties, and light-emitting diode performance of phenazine-based derivatives with three, five, and nine fused six-membered rings," Journal of Organic Chemistry, vol. 80, no. 6, pp. 30303035, 2015.

[7] Q. Zhang, Y. Divayana, J. Xiao et al., "Synthesis, characterization, and bipolar transporting behavior of a new twisted polycyclic aromatic hydrocarbon: $1^{\prime}, 4^{\prime}$-Diphenyl-naphtho- $\left(2^{\prime} .3^{\prime}\right.$ :1.2)-pyrene- $6{ }^{\prime}$-nitro- $7^{\prime}$-methyl Carboxylate," Chemistry $A$ European Journal, vol. 16, no. 25, pp. 7422-7426, 2010.

[8] Y. Yuan, J. X. Chen, F. Lu et al., "Bipolar phenanthroimidazole derivatives containing bulky polyaromatic hydrocarbons for nondoped blue electroluminescence devices with high efficiency and low efficiency roll-off," Chemistry of Materials, vol. 25, no. 24, pp. 4957-4965, 2013.

[9] M. Segal, M. Singh, K. Rivoire, S. Difley, T. van Voorhis, and M. A. Baldo, "Extrafluorescent electroluminescence in organic light-emitting devices," Nature Materials, vol. 6, no. 5, pp. 374-378, 2007.

[10] H. Nakanotani, T. Higuchi, T. Furukawa et al., "Highefficiency organic light-emitting diodes with fluorescent emitters," Nature Communications, vol. 5, no. 1, pp. 40164022, 2014.

[11] L. Zhang, S. Hu, J. Chen et al., "A series of energy-transfer copolymers derived from fluorene and 4,7-dithienylbenzotriazole for high efficiency yellow, orange, and white lightemitting diodes," Advanced Functional Materials, vol. 21, no. 19 , pp. 3760-3769, 2011.

[12] W. Yuan, P. Lu, S. Chen et al., "Changing the behavior of chromophores from aggregation-caused quenching to aggregation-induced emission: development of highly efficient light emitters in the solid state," Advanced Materials, vol. 22, no. 19, pp. 2159-2163, 2010.

[13] M. A. Baldo, D. F. O'Brien, Y. You et al., "Highly efficient phosphorescent emission from organic electroluminescent devices," Nature, vol. 395, no. 6698, pp. 151-154, 1998.

[14] S. J. Yeh, M. F. Wu, C. T. Chen et al., "New dopant and host materials for blue-light-emitting phosphorescent organic electroluminescent devices," Advanced Materials, vol. 17, no. 3, pp. 285-289, 2005. 
[15] Y. Zhang and S. R. Forrest, "Triplets contribute to both an increase and loss in fluorescent yield in organic light emitting diodes," Physical Review Letters, vol. 108, no. 26, p. 267404, 2012.

[16] J. Hu, Y.-J. Pu, F. Satoh et al., "Bisanthracene-based donoracceptor-type light-emitting dopants: highly efficient deepblue emission in organic light-emitting devices," Advanced Functional Materials, vol. 24, no. 14, pp. 2064-2071, 2014.

[17] H. Uoyama, K. Goushi, K. Shizu, H. Nomura, and C. Adachi, "Highly efficient organic light-emitting diodes from delayed fluorescence," Nature, vol. 492, no. 7428, pp. 234-238, 2012.

[18] K. Kawasumi, T. Wu, T. Zhu et al., "Thermally activated delayed fluorescence materials based on homoconjugation effect of donor-acceptor triptycenes," Journal of the American Chemical Society, vol. 137, no. 37, pp. 11908-11911, 2015.

[19] Y. Tao, K. Yuan, T. Chen et al., "Thermally activated delayed fluorescence materials towards the breakthrough of organoelectronics," Advanced Materials, vol. 26, no. 47, pp. 79317958, 2014.

[20] C. Y. Chan, L. S. Cui, J. U. Kim, H. Nakanotani, and C. Adachi, "Rational molecular design for deep-blue thermally activated delayed fluorescence emitters," Advanced Functional Materials, vol. 28, no. 11, p. 1706023, 2018.

[21] W. Y. Hung, G. C. Fang, Y. C. Chang et al., "Highly efficient bilayer interface exciplex for yellow organic light-emitting diode," ACS Applied Materials \& Interfaces, vol. 5, no. 15, pp. 6826-6831, 2013.

[22] T. Noda, H. Ogawa, and Y. Shirota, "A blue-emitting organic electroluminescent device using a novel emitting amorphous molecular material, 5,5'-bis(dimesitylboryl)-2,2'-bithiophene," Advanced Materials, vol. 11, no. 4, pp. 283-285, 1999.

[23] S. Lee, K. H. Kim, D. Limbach, Y. S. Park, and J. J. Kim, "Low roll-off and high efficiency orange organic light emitting diodes with controlled co-doping of green and red phosphorescent dopants in an exciplex forming co-host," Advanced Functional Materials, vol. 23, no. 33, pp. 4105-4110, 2013.

[24] B. Zhao, Y. Miao, Z. Wang et al., "Highly efficient orange fluorescent OLEDs based on the energy transfer from bilayer interface exciplex," Organic Electronics, vol. 37, pp. 1-5, 2016.

[25] J. Kalinowski, M. Cocchi, D. Virgili, V. Fattori, and J. A. G. Williams, "Mixing of excimer and exciplex emission: a new way to improve white light emitting organic electrophosphorescent diodes," Advanced Materials, vol. 19, no. 22, pp. 40004005, 2007.

[26] H. Cao, X. Gao, and C. Huang, "Electroplex emission from a layer of a mixture of a europium complex and tris(8-quinolinolato) aluminum," Applied Surface Science, vol. 161, no. 3-4, pp. 443-447, 2000.

[27] L. Wen, F. Li, J. Xie et al., "Electroplex emission at PVK/Bphen interface for application in white organic light-emitting diodes," Journal of Luminescence, vol. 131, no. 11, pp. 22522254, 2011.

[28] W. Song, J. Y. Lee, Y. J. Cho, H. Yu, H. Aziz, and K. M. Lee, "Electroplex as a new concept of universal host for improved efficiency and lifetime in red, yellow, green, and blue phosphorescent organic light-emitting diodes," Advanced Science, vol. 5, no. 2, p. 1700608, 2018.

[29] J. Yang, J. Huang, Q. Li, and Z. Li, “Blue AIEgens: approaches to control the intramolecular conjugation and the optimized performance of OLED devices," Journal of Materials Chemistry $C$, vol. 4, no. 14, pp. 2663-2684, 2016.
[30] J. Huang, N. Sun, Y. Dong et al., "Similar or totally different: the control of conjugation degree through minor structural modifications, and deep-blue aggregation-induced emission luminogens for non-doped OLEDs," Advanced Functional Materials, vol. 23, no. 18, pp. 2329-2337, 2013.

[31] X. Zhan, Z. Wu, Y. Lin et al., "Benzene-cored AIEgens for deep-blue OLEDs: high performance without holetransporting layers, and unexpected excellent host for orange emission as a side-effect," Chemical Science, vol. 7, no. 7, pp. 4355-4363, 2016.

[32] X. Zhan, N. Sun, Z. Wu et al., "Polyphenylbenzene as a platform for deep-blue OLEDs: aggregation enhanced emission and high external quantum efficiency of $3.98 \%$," Chemistry of Materials, vol. 27, no. 5, pp. 1847-1854, 2015.

[33] Y. Xie and Z. Li, "Triboluminescence: recalling interest and new aspects," Chem, vol. 4, no. 5, pp. 943-971, 2018.

[34] Z. Yang, Z. Chi, Z. Mao et al., "Recent advances in mechanoresponsive luminescence of tetraphenylethylene derivatives with aggregation-induced emission properties," Materials Chemistry Frontiers, vol. 2, no. 5, pp. 861-890, 2018.

[35] C. Wang, B. Xu, M. Li et al., "A stable tetraphenylethene derivative: aggregation-induced emission, different crystalline polymorphs, and totally different mechanoluminescence properties," Materials Horizons, vol. 3, no. 3, pp. 220-225, 2016.

[36] B. Di and Y. Chen, "Recent progress in organic mechanoluminescent materials," Chinese Chemical Letters, vol. 29, no. 2, pp. 245-251, 2018.

[37] D. Zhang, X. Song, M. Cai, H. Kaji, and L. Duan, "Versatile indolocarbazole-isomer derivatives as highly emissive emitters and ideal hosts for thermally activated delayed fluorescent OLEDs with alleviated efficiency roll-off," Advanced Materials, vol. 30, no. 7, p. 1705406, 2018.

[38] R. Furue, T. Nishimoto, I. S. Park, J. Lee, and T. Yasuda, "Aggregation-induced delayed fluorescence based on donor/acceptor-tethered janus carborane triads: unique photophysical properties of nondoped OLEDs," Angewandte Chemie International Edition, vol. 55, no. 25, pp. 7171-7175, 2016.

[39] J. Guo, X. L. Li, H. Nie et al., “Achieving high-performance nondoped OLEDs with extremely small efficiency roll-off by combining aggregation-induced emission and thermally activated delayed fluorescence," Advanced Functional Materials, vol. 27, no. 13, p. 1606458, 2017.

[40] B. Xu, H. Wu, J. Chen et al., "White-light emission from a single heavy atom-free molecule with room temperature phosphorescence, mechanochromism and thermochromism," Chemical Science, vol. 8, no. 3, pp. 1909-1914, 2017.

[41] J. Kalinowski, M. Cocchi, P. D. Marco, W. Stampor, G. Giro, and V. Fattori, "Impact of high electric fields on the charge recombination process in organic light-emitting diodes," Journal of Physics D: Applied Physics, vol. 33, no. 19, pp. 23792387, 2000.

[42] J. Li, Z. Xu, F. Zhang et al., "Electroplex emission of the blend film of PVK and DPVBi," Solid-State Electronics, vol. 54, no. 4, pp. 349-352, 2010.

[43] Q. Peng, A. Li, Y. Fan, P. Chen, and F. Li, "Studying the influence of triplet deactivation on the singlet-triplet interconversion in intra-molecular charge-transfer fluorescencebased OLEDs by magneto-electroluminescence," Journal of Materials Chemistry C, vol. 2, no. 31, pp. 6264-6268, 2014. 
[44] D. Zhang, L. Duan, Y. Li et al., "Towards high efficiency and low roll-off orange electrophosphorescent devices by fine tuning singlet and triplet energies of bipolar hosts based on indolocarbazole/1,3,5-triazine hybrids," Advanced Functional Materials, vol. 24, no. 23, pp. 3551-3561, 2014.

[45] C. Liu, Q. Fu, Y.Zou, C. Yang, D. Ma, and J. Qin, "Low turn-on voltage, high-power-efficiency, solution-processed deep-blue organic light-emitting diodes based on starburst oligofluorenes with diphenylamine end-capper to enhance the HOMO level," Chemistry of Materials, vol. 26, no. 10, pp. 3074-3083, 2014.

[46] W. Y. Hung, P. Y. Chiang, S. W. Lin et al., "Balance the carrier mobility to achieve high performance exciplex OLED using a triazine-based acceptor," ACS Applied Materials \& Interfaces, vol. 8, no. 7, pp. 4811-4818, 2016.

[47] M. M. Rothmann, S. Haneder, E. da Como, C. Lennartz, C. Schildknecht, and P. Strohriegl, "Donor-substituted 1,3,5triazines as host materials for blue phosphorescent organic light-emitting diodes," Chemistry of Materials, vol. 22, no. 7, pp. 2403-2410, 2010. 